\title{
Mental Health and Attitude toward Substance use among Medical Students
}

\author{
Ali Mohammad-Beigi *1, 2, Mahsa Babaei ${ }^{3}$ \\ ${ }^{1}$ Clinical Psychologist, Shahid Beheshti University of medical sciences, Tehran, Iran. \\ ${ }^{2}$ Clinical Psychologist, Loghman Hakim hospital, Tehran, Iran. \\ ${ }^{3}$ Medical Doctor, Faculty of medicine, Shahid Beheshti University of medical sciences, Tehran, Iran.
}

Corresponding Author: Ali Mohammad Beigi, Clinical Psychologist, Shahid Beheshti University of medical sciences, Tehran, Iran.

Received date: October 04, 2021; Accepted date: November 24, 2021; Published date: January 03, 2022

Citation: Ali Mohammad-Beigi and Mahsa Babaei (2022) Mental Health and Attitude toward Substance use among Medical Students. J. Psychology and Mental Health Care, 6(1): DOI: 10.31579/2637-8892/146

Copyright: (C) 2022, Ali Mohammad Beigi, This is an open access article distributed under the Creative Commons Attribution License, which permits unrestricted use, distribution, and reproduction in any medium, provided the original work is properly cited.

\begin{abstract}
Introduction: Medical students are important and vulnerable populations. High levels of stress, financial dependency, easy access to substances, and lack of adequate support increase their mental health problems and substance use. In this study, we aimed to investigate the relationship between their mental health status and attitude toward substances.
\end{abstract}

Methods: In this cross-sectional study, a total of 157 medical students were enrolled using the convenient sampling method, to answer the Drug Attitude Scale test and General Health Questionnaire. Data were analyzed using the SPSS.

Results: Mental health is significantly correlated with the attitude toward substance use. The participants in this study had mental health problems in general. Half of them also had a positive attitude and tendency to use substances.

Conclusion: Mental health problems and tendency to use the substances were prevalent among medical students. More investigations and designation of therapeutic and preventive programs are necessary especially for vulnerable populations.

Keywords: attitude; substance use disorder; medical students; prevention; mental health

\section{Introduction}

According to the Diagnostic and Statistical Manual of Mental Disorders, $5^{\text {th }}$ Edition, the term "Substance Use Disorder" (SUD) is referred to a set of cognitive, behavioral, and physiological symptoms as a result of using substances in an excessive amount or for a long period of time. Although being aware of its harmful consequences, the individual extremely desires to use it. SUD is usually associated with lower levels of self-control and through activating the reward system, it gives a feeling of pleasure to the user and makes them feel an urge to use the substance. The user spends a lot of time to reach and use the substance and recover from its effects. SUD also causes many substance-induced physical, psychological, and social disorders to the individual, failure to fulfill their academic or professional obligations, and withdrawal from their family and society (American Psychiatric Association, 2013).

SUD is a highly prevalent and growing issue among societies. According to the literature, about $17 \%$ of US adults are involved in substance and alcohol use problems (Wu et al., 2003). Interestingly, the prevalence of SUD reaches its peak during late adolescence and early adulthood, which makes this period highly critical and important in this regard (SAMHSA, 2011).

SUD is an important disaster for societies, and causes many social, economic, health-related, and psychological consequences (Sahu \& Sahu, 2012). It can cause physical disorders such as cardiovascular and liver diseases (Pace \& Samet, 2016), and psychosocially result in hangover, academic failure (Ayala et al., 2017), mental health problems, poor peer relationships, disengagement from community activities, and familial deprivation (Sahu \& Sahu, 2012). The user's family also suffers emotionally and financially because of spending a considerable amount of money and resources for buying the substance or for the treatment of SUD besides dealing with the substance-related social stigmas (Sahu \& Sahu, 2012). The user's urge to gain the substances results in an increased amount of income-generating crimes and violence, which consequently increases the need for social justice services and endangers societies' safety, welfare, and resources (Sahu \& Sahu, 2012). Substance users also miss their academic classes or work, borrow money from friends or colleagues, get warranted by their boss or teachers, and frequently 
struggle with others (Sahu \& Sahu, 2012). Their poor functioning and low productivity are other negative consequences of SUD (Sahu \& Sahu, 2012). Considering the high prevalence of SUD, its harmful effects, and high costs, there is an emerging need for recognition of its underlying and predisposing factors, for the preparation of useful preventive and therapeutic guidelines. Accordingly, many biological, social, and psychological factors have been addressed as predisposing and underlying factors of SUD (Sahu \& Sahu, 2012). Among these factors, psychological problems especially mental health issues are of specific importance in this regard, because they are highly prevalent among populations, closely related to SUD, and greatly preventable (Sahu \& Sahu, 2012). According to the World Health Organization (WHO), (2004), Mental Health is defined as "a state of well-being in which the individual realizes his or her own abilities, can cope with the normal stresses of life, can work productively and fruitfully, and is able to make a contribution to his or her community". Mental health improves psychological well-being and happiness and increases societies' welfare and productivity (World Health Organization, 2004). In a study, about $11 \%$ of the US population have reported mental health problems (Wu et al., 2003). There is a close and complex relationship between mental health problems and SUD. For example, some mental health problems such as stress (Jose Candido al., 2018) and low emotional intelligence (Riley \& Schutte, 2003) can increase the likelihood of SUD, while factors such as aggression and depressive symptoms can occur as a result of SUD (Smithet al., 2016), and some other factors such as burnout (Molodynski et al., 2020), negative emotions (Smith et al., 2016), and suicidal risk (Smith et al.,2016), are commonly associated with SUD. Therefore, improvement of mental health can greatly affect the amount of SUD among societies, which can save a considerable amount of resources and finances, and improve societies' welfare and health. Medical students are one of the highly vulnerable populations in terms of both SUD and mental health problems (Molodynski et al., 2020; Agin et al., 2019). According to the literature, a considerable number of medical students have mental health problems (Molodynski et al., 2020). For example, 52.4\% of medical students have reported high levels of stress, which is mostly due to their difficult courses, many exams, and limited time. It can cause mental instability, impaired judgment, missing classes, and decreased functioning. It can also cause the secretion of excessive amounts of cortisol, which results in multiple physical disorders (Melaku et al., 2015). Mental health problems can decrease their concentration and learning ability, which decreases their academic performance and results in a decreased patient care in the future (Melaku et al., 2015). Besides, being a student for a long time, through spending finances with no income, imposes high stress on them and endangers their mental health (Melaku et al., 2015). Moreover, there is a high prevalence of SUD among medical students in most of the studies. Studies have reported that $35.6 \%$ of medical students have reported alcohol consumption (Melaku et al. 2015 ) and $79 \%$ have reported cannabis use (Molodynskiet al., 2020). One reason is that using the substance can temporarily relieve the individual from academic and environmental stressors (Ayala et al., 2017). Several other factors including impaired self-control (America Psychiatric Association, 2013), poor relationships, lack of support groups (Baldisseri, 2007), and easy access to substances can also increase the prevalence of SUD among medical students (Ayala et al., 2017). They are an important population because of several reasons. First, their critical age of early adulthood with its developmental sensitivity and major social, psychological, and physiological changes makes them more vulnerable and necessitates the designation of appropriate and accessible mental health services and preventive programs for them. Investing in the improvement of their mental health and prevention of SUD of these young people results in many social, economic, psychological, and health benefits with lower costs (McGorry et al., 2007). Secondly, they are future doctors, directly related to people's health, and an important part of society's workforce that a huge amount of finance and resources have been spent for their education (Baldisseri, 2007). Therefore, we aimed to investigate the relationship between mental health status and attitude toward substance abuse among medical students to help to understand the causes and consequences of SUD among these highly important and vulnerable populations and help them in the prevention and treatment of these disorders.

\section{Material and method}

\subsection{Study design and sampling technique}

This cross-sectional questionnaire survey study was conducted on medical students of "Shahid Beheshti University of Medical Sciences", one of the top medical universities in Iran. A total of 170 participants were enrolled in the study using the convenient sampling method. The required sample size was estimated using single population proportion formula with a $95 \%$ confidence interval and a $5 \%$ margin of error.

\subsection{Data collection}

Data was collected using the Drug Attitude Scale (DAS) and General Health Questionnaire (GHQ-28). The questionnaires were provided anonymously and the participants were assured about the lack of any personal data interpretation. Informed consent was properly obtained both written and verbally. A total of 157 well-answered questionnaires were returned and entered into the study.

The DAS was used to evaluate the participants' attitude toward substance use, which was designed by Campbell and Chang (2006). The test includes 25 items, and the participants were asked to rate each item based on a five-point Likert scale ranging from totally disagree to totally agree. Then they are divided into five categories based on the scores they earned on this test. Earning a total score of 37 and below indicates being in the Extremely Positive category, a total score of 38-44 indicates the Positive category, a total score of 45-53 places the participant in the Neutral category, earning a score of 54-64 puts the respondent in the Negative category, and a score of 65 and higher indicates being in the Extremely Negative category. The internal consistency was evaluated using Cronbach's Alpha, and was reported $87 \%$ for the test, $87 \%$ for the clinical scale, and $89 \%$ for the attitude scale. After translation and validation of the test in Persian, it has been approved by experts in Iran. The test validity was calculated in this study using Cronbach's alpha and reported 0.75 for the test, 0.64 for the clinical subscale, and 0.65 for the attitude subscale.

The GHQ-28, invented by Goldberg (1972), was used to assess the participants' general health status. It includes 28 items for the assessment of physical symptoms, anxiety, sleep disorders, social dysfunction, depression, and suicidal tendency. Each item is scored based on a fourpoint Likert scale ranging from 0 to 3 . A higher score indicates more symptoms and general health problems. After translation and validation of the test in Persian, experts have calculated the test validity using the test-re-test method and reported it 0.89 . They also reported test sensitivity, specificity, and total amount of error with cutoff point of 22 respectively as $0.84,0.74$, and 0.2 .

\section{Results}

As shown in Table 1, the mean and standard deviation (SD) of participants' total DAS score $(\mathrm{M}=51.38, \mathrm{SD}=9.65)$ is calculated. It indicates that the participants have a neutral attitude to the substance in general. Additionally, $49.7 \%$ of the participants have a negative attitude toward substances and $1.9 \%$ have an extremely negative attitude toward substances. 


\begin{tabular}{|l|l|l|l|l|l|l|}
\hline variable & $\begin{array}{l}\text { Number } \\
\text { Total }\end{array}$ & $\begin{array}{l}\text { Mean \& SD } \\
\text { Total }\end{array}$ & males & $\begin{array}{l}\text { Mean \& SD } \\
\text { Males }\end{array}$ & $\begin{array}{l}\text { Numbers } \\
\text { Females }\end{array}$ & $\begin{array}{l}\text { Mean \& SD } \\
\text { Females }\end{array}$ \\
\hline Extremely positive & 16 & $33.62 \pm 4.01$ & 7 & $31.57 \pm 4.86$ & 9 & $35.22 \pm 2.44$ \\
\hline positive & 23 & $41.22 \pm 1.76$ & 13 & $41.00 \pm 1.87$ & 10 & $41.50 \pm 1.65$ \\
\hline Neutral & 37 & $48.81 \pm 2.38$ & 14 & $48.50 \pm 2.50$ & 23 & $49.00 \pm 2.34$ \\
\hline Moderately negative & 78 & $58.22 \pm 2.61$ & 28 & $57.86 \pm 2.51$ & 49 & $58.43 \pm 2.69$ \\
\hline Extremely negative & 3 & $77.67 \pm 7.57$ & 1 & $81.00 \pm 00$ & 2 & $76.00 \pm 9.90$ \\
\hline Total DAS & 157 & $51.38 \pm 9.65$ & 63 & $49.75 \pm 10.30$ & 93 & $52.41 \pm 9.11$ \\
\hline
\end{tabular}

Table1. Mean and standard deviation of total DAS score and its subscales divided by gender

According to Table 2, the mean total participants' score on social withdrawal problems $(\mathrm{M}=7.74, \mathrm{SD}=4.07)$ is higher than the cutoff point, which indicates that they have problems in this aspect. Besides, the mean total participants' GHQ scores $(\mathrm{M}=24.62$, $\mathrm{SD}=1.35)$ is higher than the cutoff point of 22, indicating mild psychological problems among them.

\begin{tabular}{|c|c|c|c|c|c|c|c|c|}
\hline variable & $\begin{array}{l}\text { Total } \\
\text { Number }\end{array}$ & $\begin{array}{l}\text { Mean \& SD } \\
\text { Total }\end{array}$ & $\begin{array}{l}\% \\
\text { healthy }\end{array}$ & $\begin{array}{l}\text { \%unhealth } \\
\mathrm{y}\end{array}$ & $\begin{array}{l}\text { Male } \\
\text { number }\end{array}$ & $\begin{array}{l}\text { Male } \\
\text { Mean\& SD }\end{array}$ & $\begin{array}{l}\text { Female } \\
\text { number }\end{array}$ & $\begin{array}{l}\text { Female } \\
\text { mean \&SD }\end{array}$ \\
\hline $\begin{array}{l}\text { Somatic Symptoms } \\
\text { problems }\end{array}$ & 157 & $5.90 \pm 3.99$ & 64.70 & 35.30 & 63 & $6.29 \pm 4.57$ & 93 & $5.66 \pm 3.56$ \\
\hline $\begin{array}{l}\text { Anxiety and Sleep } \\
\text { problems }\end{array}$ & 157 & $6.35 \pm 4.47$ & 57.10 & 42.90 & 63 & $6.21 \pm 5.27$ & 93 & $6.43 \pm 3.90$ \\
\hline $\begin{array}{l}\text { Social Withdrawal } \\
\text { problems }\end{array}$ & 157 & $7.74 \pm 4.07$ & 39.10 & 60.90 & 63 & $7.49 \pm 4.15$ & 93 & $7.86 \pm 4.03$ \\
\hline Depression problems & 157 & $4.63 \pm 5.19$ & 71.20 & 28.80 & 63 & $4.94 \pm 5.92$ & 93 & $4.38 \pm 4.66$ \\
\hline $\begin{array}{l}\text { GHQ(General Health } \\
\text { Questionnaire) }\end{array}$ & 157 & $24.62 \pm 14.85$ & 55.80 & 44.20 & 63 & $24.92 \pm 17.95$ & 93 & $24.32 \pm 12.49$ \\
\hline
\end{tabular}

Table.2 Mean and standard deviation of total GHQ score and its subscales divided by gender

Females have higher mean total score in the aspects of anxiety and sleep problems and social withdrawal problems than males, which is indicative of more problems among females in these aspects. Besides, females earned lower mean total GHQ scores than males, which indicates better

general health status among female participants in this study.
According to Table 3, the total DAS score has a significantly positive correlation with participants' total scores in the somatic symptoms $(\mathrm{R}=0.195, \mathrm{P}<0.05)$, anxiety and sleeplessness $(\mathrm{R}=0.213, \mathrm{P}<0.01)$, social withdrawal problems $(\mathrm{R}=0.235, \mathrm{P}<0.01)$, depression and suicidal tendency $(\mathrm{R}=0.258, \mathrm{P}<0.01)$, and total symptoms $(\mathrm{R}=0.257, \mathrm{P}<0.01)$.

\begin{tabular}{|l|l|l|l|l|l|l|l|l|}
\hline Variables & $\begin{array}{c}\text { Attitude } \\
\text { scale }\end{array}$ & $\begin{array}{c}\text { Clinical } \\
\text { scale }\end{array}$ & $\begin{array}{c}\text { Total } \\
\text { DAS }\end{array}$ & $\begin{array}{c}\text { Extremely } \\
\text { positive }\end{array}$ & positive & $\begin{array}{c}\text { Neutral } \\
\text { Moderately } \\
\text { negative }\end{array}$ & $\begin{array}{c}\text { Extremely } \\
\text { negative }\end{array}$ \\
\hline $\begin{array}{c}\text { Somatic Symptoms } \\
\text { problems (A) }\end{array}$ & $\mathrm{N}=157$ & $\mathrm{~N}=157$ & $\mathrm{~N}=157$ & $\mathrm{~N}=16$ & $\mathrm{~N}=23$ & $\mathrm{~N}=37$ & $\mathrm{~N}=78$ \\
\hline $\begin{array}{c}\text { Anxiety and Sleep } \\
\text { problems (B) }\end{array}$ & $.205^{*}$ & .154 & $.195^{*}$ & 1.000 & 1.000 & 1.000 & 1.000 \\
\hline $\begin{array}{c}\text { Social Withdrawal } \\
\text { problems (C) }\end{array}$ & .132 & $.253^{* *}$ & $.235^{* *}$ & .251 & .309 & $.439^{* *}$ & $.600^{* *}$ & 1.000 \\
\hline $\begin{array}{c}\text { Depression problems } \\
\text { (D) }\end{array}$ & $.163^{*}$ & $.281^{* *}$ & $.258^{* *}$ & $.524^{*}$ & $.514^{*}$ & .227 & $.448^{* *}$ & $.860^{* *}$ \\
\hline $\begin{array}{c}\text { GHQ(General Health } \\
\text { Questionnaire) }\end{array}$ & $.173^{*}$ & $.260^{* *}$ & $.257^{* *}$ & .474 & .404 & $.533^{* *}$ & $.748^{* *}$ & $1.000^{* *}$ \\
\hline
\end{tabular}

$* * \mathrm{p}<0.01 \quad * \mathrm{p}<0.05 \quad \mathrm{~N}=157$

Table. 3 Correlation matrix of mean total DAS score and its subscales with mean total GHQ scores and its subscales divided by gender

Moreover, there are significantly positive relationships between extremely positive attitude toward substance with depression and suicidal tendency $(\mathrm{R}=0.524, \mathrm{P}<0.05)$, positive attitude toward substance with depression and suicidal tendency $(\mathrm{R}=0.514, \mathrm{P}<0.05)$, neutral attitude toward substance with anxiety and sleep problems $(\mathrm{R}=0.434, \mathrm{P}<0.01)$, neutral attitude toward substance with social withdrawal symptoms $(\mathrm{R}=0.439, \mathrm{P}<0.01)$, and neutral attitude toward substance with general symptoms $(\mathrm{R}=0.533, \mathrm{P}<0.01)$.

The negative attitude toward the substances has also a significantly positive relationship with anxiety and sleep problems $(\mathrm{R}=0.587, \mathrm{P}<0.01)$, social withdrawal symptoms $(\mathrm{R}=0.600, \mathrm{P}<0.01)$, depression and suicidal tendency $(\mathrm{R}=0.448, \mathrm{P}<0.01)$, and the general symptoms $(\mathrm{R}=0.748$, $\mathrm{P}<0.01)$.
The extremely negative attitude toward substance has also a significantly positive relationship with anxiety and sleep problems $(\mathrm{R}=1, \mathrm{P}<0.01)$, social withdrawal symptoms $(\mathrm{R}=1, \mathrm{P}<0.01)$, and general symptoms $(\mathrm{R}=1$, $\mathrm{P}<0.01)$

Moreover, there are significantly positive relationships between the attitude toward substance scale with anxiety and sleep problems $(\mathrm{R}=0.205, \mathrm{P}<0.05)$, social withdrawal symptoms $(\mathrm{R}=0.235, \mathrm{P}<0.01)$, depression and suicidal tendency $(\mathrm{R}=0.163, \mathrm{P}<0.05)$, and general symptoms $(\mathrm{R}=0.173, \mathrm{P}<0.05)$.

There are also significantly positive relationships between the clinical scale of DAS test with anxiety and sleep problems $(\mathrm{R}=0.176, \mathrm{P}<0.05)$, 
social withdrawal symptoms $(\mathrm{R}=0.253, \mathrm{P}<0.01)$, depression and suicidal tendency $(\mathrm{R}=0.281, \mathrm{P}<0.01)$, and general symptoms $(\mathrm{R}=0.260, \mathrm{P}<0.01)$.

\section{Discussion}

Our aim in this study was to investigate any possible relationship between the attitude toward substance abuse and mental health among the vulnerable population of youth, especially medical students. The results may help to the development of effective preventive and therapeutic programs targeted to youth populations, students, and a highly vulnerable population of medical students.

According to the results, $49.7 \%$ of the sampled medical student have a negative attitude toward substance use and $1.9 \%$ have an extremely negative attitude toward substance use. A negative attitude toward substance use indicates a higher propensity to using the substances. Therefore, about half of the medical students are highly potent to use substances if they get the chance. Despite being aware of its harmful consequences, medical students refuse to accept the harmful physical, social, and psychological dangers of substance use. They are highly important in this regard because they are future doctors and are directly related to other people's health. Their underestimation of harmful consequences of substance use results in their future professional malpractice in a way that they will not refer substance user patients to specialists and will not promote the prevention and treatment of SUD.

The participants in this study earned a mean total social withdrawal problem scores higher than the cut-off point, which is indicative of their problems in this aspect. Their mean total mental health score is also higher than the cutoff point of 22 which is indicative of these medical students' mental health problems.

Female medical students had higher mean total scores on Anxiety and Sleep problems and Social Withdrawal problems than males, which shows that female medical students in this study have more problems in these aspects than males. Moreover, male medical students earned higher mean total scores in Somatic Symptoms problems and Depression and suicidal tendency than females, indicative of more problems in these aspects among male medical students than females.

Female medical students' mean total mental health score was higher than males, which reveals female medical students' better mental health status. Medical students in this study earned a mean total Social Withdrawal problems score higher than the cutoff point. According to the cognitive approach, it can be as a result of medical students' higher levels of negative and destroying attitudes and beliefs, which increase their tendency to use substances as a relief. According to Bostic (2003), mental vitality is defined as highly energetic internal experiences, which provide mental and physical power to experience energy, delight and vitality (Ryan \& Deci, 2008). According to the high levels of psychological symptoms and low levels of physical and mental vitality among these medical students, they are more potent to use the substances. Moreover, mental health is significantly related to the attitude toward substance use among these students, and their better mental health status results in less substance use. This relationship is more significantly evident between mental health with the negative attitude to substance use and extremely negative attitude to substance use. This is because individuals with these attitudes refuse to understand and accept harms and risks of substance use.

In this study, mental health was also significantly correlated with both the clinical and attitude subscales of the DAS test, with a more prominent relationship with the clinical subscale, which are consistent with previous studies Kenney et al., (2000), Chisolm et al., (2009), Hovey (2001), and Feeney et al., (2006).

According to the literature, psychological problems especially anxiety and depression (Moody et al., 2016), and mental disorders are significantly correlated with SUD (Regier et al., 1990; Asselmann et al., 2014; Kessler, 2004; Agosti et al., 2002) and predispose and cause the individuals to use substances (Buckner et al., 2007). Moreover, a positive attitude toward substance use is a proved risk factors for SUD (Chabrol et al., 2004; Pandina, 2001).

The reason why students refuse to understand and accept the risks and harms of using the substance can be explained with multiple approaches. According to the Perceived Stress Theory, stress is a psychological condition or process by which the individual perceives that his/her physical and mental health is at risk. Therefore, formation of stress is depended on the way the individual perceives situations and events. While some people believe that SUD among adolescents and youths is a response to an increase in their stressful life and lack of coping skills (Merrill \& Thomas, 2013; Wong et al., 2013). Conclusively, SUD can be a result of improper dealing with daily challenges and negative affective experiences (Shafeie Amiri \& Ariaie Far, 2012; Chiong et al., 2010; Bobadilla \& Taylor, 2007).

According to the studies, people use the substance to relief their negative internal experiences (Hayes et al., 2003). Besides, substance users report more negative emotions, impatience, exhaustion, loneliness, shame, anxiety, worrisome, argument, mental pressure, stress due to familial problems, and lower self-esteem than others (Cloninger, 2004). SUD is also a general coping mechanism which is used in situations with no other coping mechanisms present (Hanh, 1991). Therefore, the students with higher levels of psychological and emotional disorders seek more relief for their problems, and they are more potent to use substance in order to escape from their problems.

Accordingly, psychological capital is a constantly growing positive psychological factor, which includes resilience, optimism, hope and selfefficacy and predicts an individual's functioning and satisfaction better than any other variable. This personal factor helps people to dominate their negative emotions and increases their welfare (Tugged et al., 2004). In this study, total students' mental health score is higher than the cut-off point and they generally have mild mental disorders and have lower levels of psychological capital. Therefore, they are unable to properly deal with their stress and have low levels of the feelings of self-worth and selfesteem, and possess a negative, fragile, foreigner and critical perception of themselves, which makes them more prone to use substances as a relief to decrease their stress and mental distress (Chen \& Jang, 2010). Another reason for high consumption of substances is that some people use it as a relief for their physical pain and problems (Blume et al., 2000; Green et al., 2012). Several factors including genetics have also been addressed to cause SUD and mental health problems, and define the high prevalence and co-occurrence of these disorders (Merikangas et al., 1998; McGee et al., 2000; Moody et al., 2016). Therefore, genetic disorders can cause more negative emotions and psychological problems which can lead to more SUD (Kornor \& Nordvik, 2007; Terracciano et al., 2008). Therefore, determination of the underlying factors of SUD can help us in preventive and therapeutic programs. It has been suggested to design population based studies and programs, with more emphasis on more vulnerable populations and those with lower costs and higher benefits such as adolescents, youths, students, and specifically medical students.

\section{Conclusion}

Mental health problems and propensity to use the substances was highly prevalent among a sample of third year pre-clinical medical students in this study. preventive and therapeutic programs are needed to be targeted to this highly important and vulnerable population to prevent the high risks and costs that their SUD and mental health problems can impose on societies. In this study SUD was significantly related to mental health problems which indicates that the concomitant consideration of these disorders can be highly beneficial. For example, improvement of medical 
students' mental health status can decrease their likelihood of using the substances. Further investigations are needed to better clarify the nature of the relationship between mental health status and SUD especially among vulnerable populations including youths and medical students.

Substance use disorder is a prevalent issue among societies. Many factors have been addresses as its underlying and related factors. Mental health problems are among the most important factors, which are closely related to substance use disorders. They can cause, associate with, or be a result of substance use. Increasing our understanding of the relationship between these factors can help us to provide therapeutic and preventive programs for substance use disorders and improvement of mental health among vulnerable populations. Medical students are among the highly vulnerable and important populations in this regard. They are future doctors and directly related to people's health. Besides, they are in a critical age of early adulthood when most of substance use disorders happen, and due to their easy access to substances and adequate knowledge about how to use them increases the possibility of their substance use. Their psychological problems with high levels of chronic stress causes them to use the substances as a relief for their problems and pain. Underestimation of SUD results in their poor professional functioning in the future by affecting their social, mental, and physical health, and prevents them to refer the substance user patients to the specialists. They also will not promote substance use prevention and treatment among the societies as health care providers and a rapid increase in the prevalence of SUD will be observed. Therefore, specific consideration is needed for this important and vulnerable population, and therapeutic and preventive guidelines with more support and awareness targeted at this population are necessary.

\section{Acknowledgement}

We thank all medical students who helped us to conduct this study with their cooperation.

\section{Ethics}

All content of this research adheres with the ethical guidelines developed by the Committee on Publication Ethics (COPE) during the 2nd World Conference on Research Integrity in Singapore in 2010. All parts of this study meets the American Psychological Association's (APA) Ethical Principles of Psychologists and Code of Conduct (the Ethics Code) and adheres to the legal requirements of the study country, Iran.

\section{Conflict of interest}

The authors declare that they have no conflict of interests for this study.

\section{Funding}

None of the authors received any funding for this study.

\section{References}

1. Agin K, Dehaghi AMB, Babaei M (2019) Assessment of the Relationship between Attitude toward Substance Abuse and Early Maladaptive Schemas in Medical Students. J Psychol Psychother 9:353. doi: 10.35248/2161-0487.19.9.353

2. Agosti, E. Nunes, and F. Levin. (2002). Rates of psychiatric comorbidity among U.S. residents with lifetime cannabis dependence, American Journal of Drug and Alcohol Abuse, vol. 28 , no. 4, pp. 643-652.

3. American Psychiatric Association (2013). Diagnostic and Statistical Manual of Mental Disorders, 5th Edition: DSM-5.

4. Andrew Molodynski, T. L., Murtaza Kadhum, Sarah Marie Farrell, Maha Lemtiri Chelieh, Telma Falcão De Almeida, et al. (2020). Cultural variations in wellbeing, burnout and substance use amongst medical students in twelve countries. International Review of Psychiatry. doi:10.1080/09540261.2020.1738064.

5. Asselmann, H.-U. Wittchen, R. Lieb, M. Höfler, and K. BeesdoBaum.(2014). Associations of fearful spells and panic attacks with incident anxiety, depressive, and substance use disorders: A 10year prospective-longitudinal community study of adolescents and young adults," Journal of Psychiatric Research, vol. 55, no. 1, pp. 8-14.

6. Baldisseri, M. R. (2007). Impaired healthcare professional. Crit Care Med, 35(2).

7. Blume, A.W.; Scaling, K.B.; \& Marlatt, G.A. (2000). Revisiting the self-medication hypothesis from a Behavioral perspective. Cognitive Behavior Practice, 7, 379-84.

8. Brian C. Smith, A. P. A., Jessica M. Boarts, Douglas L. Delahanty \& Miquel Brazil. (2016). PTSD, Depression, and Substance Use in Relation to Suicidality Risk among Traumatized Minority Lesbian, Gay, and Bisexual Youth. Archives of Suicide Research, 20(1), 80-93. doi:10.1080/13811118.2015.1004484.

9. Bobadilla L, Taylor J. (2007). Relation of physiological reactivity and perceived coping to substance use disorders. Addictive behaviors. 2007;32(3):608-16.

10. Bostic, JH (2003). constractive thinking, Mental Health and physical Health, Unpublished Ph.D dissertation, Saint Louis University.

11. Buckner JD, Keough ME, Schmidt NB.(2007). Problematic alcohol and cannabis use among young adults: The roles of depression and discomfort and distress tolerance. Addictive behaviors; 32(9):1957.

12. Chabrol H, Massot E, Mullet E.(2004). Factor structure of cannabis related beliefs in adolescents. Addictive behaviors, 29(5):929-33.

13. Chen, K. C. \& Jang, S. J. (2010). Motivation in online learning: Testing a model of self-determination theory. Journal of Computers in Human Behavior, 26, 741-752.

14. Chiong AS, Bry BH, Johnson VL. (2010). Mediators between coping styles and substance use/intentions in urban, high school freshmen. Addictive behaviors;35(1):57-9.

15. Chisolm DJ, Mulatu MS, Brown JR.(2009). Racial/ethnic disparities in the patterns of co-occurring mental health problems in adolescents in substance abuse treatment. Journal of substance abuse treatment. 37(2):203-10.

16. Christine A Pace, J. H. S. (2016). In the Clinic. Substance Use Disorders. Ann Intern Med, 146(7). doi:10.7326/AITC201604050.

17. Cloninger, C. (2004). Feeling Good: The Science of Well-Being. New York: Oxford University Press.

18. Erin E. Ayala, D. R., Jeffrey S. Winseman \& Hyacinth R.C. Mason. (2017). Prevalence, perceptions, and consequences of substance use in medical students. 10.1080/10872981.2017.1392824, 22(1).

19. Feeney G, Connor J, Young RM, Tucker J, McPherson A.(2006). Improvement in measures of psychological distress amongst amphetamine misusers treated with brief cognitive behavioural therapy (CBT). Addictive behaviors; 31(10):1833-43.

20. Fernando José Candido, R. S., Matheo Augusto Stumpf, Luiz Gustavo Fernandes, Rafael Veiga, Matheus Santin, Ana Kluthcovsky. (2018). The use of drugs and medical students: a literature review. REV ASSOC MED BRAS 64(5), 462-468.

21. Goldberg DP.(1972) The detection of psychiatric illness by questionnaire. London: Oxford University Press; 1972.

22. Green, K.M.; Zebrak, K.A.; Robertson, J.A.; Fothergill, K.A.; \& Ensminger, M.E. (2012). Interrelationship of substance use and psychological distress over the life course among a cohort of 
urban African Americans. Drug and Alcohol Dependence, 123, 239-48.

23. Hanh, T. N. (1991). The Miracle of Mindfulness. London: Rider.

24. Hannahriley, n.s.s.(2003).low emotional intelligence as a therapy predictor of substance- use problems. J. drug education, 33(4), 391-398

25. Hayes, S. C. masuda, A. \& demey, H. (2003) Acceptance commitment therapy and the third wave of behavior theapy. Gedrags therapia (Dutch journal of Behavior therpy) 36. 69-96.

26. Hovey JD.(2001). Mental health and substance abuse. Migrant Health Issues;19: 33-47.

27. Kenney, M.F. Hansen, W.B. McNeal, R.B. (2000), Comparison of Postulated Mediators of School-Based Substance Use Prevention in Adolescents A longitudinal Examination, National Institute on Drug Abuse.

28. Kessler. (2004). The epidemiology of dual diagnosis, Biological Psychiatry, vol. 56(10), pp. 730-737. View at Publisher.

29. Kornor, H.; \& Nordvik, H. (2007). Five-factor model personality traits in opioid dependence. Journal of Drug Education, 3(37), 285-300.

30. Leta Melaku, A. M., and Alemayehu Negash. (2015). Stress among Medical Students and Its Association with Substance Use and Academic Performance. Journal of Biomedical Education.

31. Li-Tzy Wu, C. L. R., Charles E. Williams. (2003). Use of Substance Abuse Treatment Services by Persons with Mental Health and Substance Use Problems. PSYCHIATRIC SERVICES, 54(3).

32. McGee, R.; Williams, S.; Poulton, R.; Moffitt, T. (2000). A longitudinal study of cannabis use andmental health from adolescence to early adulthood. Addiction, 95(4), 491-503.

33. Merikangas, K.R.; Mehta, R.L.; Molnar, B.E.; Walters, E.E.; Swendsen, J.D.; et al. (1998). Comorbidity of substance use disorder with mood and anxiety disorders: results of the International Consortium in Psychiatric Epidemiology. Addiction Behaviore, 23(6), 893-907.

34. Merrill JE, Thomas SE. (2013). Interactions between adaptive coping and drinking to cope in predicting naturalistic drinking and drinking following a lab-based psychosocial stressor. Addictive behaviors. Addictive Behaviors; 38: 16728.

35. Moody, L.; Francka, C.; \& Bickel, W.K. (2016). Comorbid depression, antisocial personality, and substance dependence: Relationship with delay discounting. Drug and Alcohol Dependence 160, 190-6.
36. Najafi M, Solati Yaghobi N. (1987). Epidemiology of mental disorders in Gilan. (M. A. Dissertation). Tehran: Psychiatric Institute; 1987. [In Persian].

37. Pandina R J. (2001). Risk and protective model in adolescent drug use: Putting them to work for prevention.

38. Patrick D McGorry, R. P., Ian B Hickie, Anthony F Jorm. (2007). Investing in youth mental health is a best buy. MJA, 187(7).

39. D A Regier 1, M E Farmer, D S Rae, B Z Locke, S J Keith, L L Judd, F K Goodwin (1990). Comorbidity of mental disorders with alcohol and other drug abuse. Results from the epidemiologic catchment area (ECA) study. The Journal of the American Medical Association, 264:19; 2511-2518.

40. Ryan, RM.Deci, E .(2008). From ego depletion to vitality: Theory and findings concerning the facilitation of energy available to the self. Social and Personality Personality of Environmental development psychology, 2, 702-717.

41. Sahu, K. K. S. S. (2012). Substance abuse causes and consequences. Bangabasi Academic Journal, 9.

42. Samhsa. (2011). Results from the 2010 National Survey on Drug Use and Health: Summary of National Findings vol NSDUH Series H-41, HHS Publication No. (SMA) 11-4658. Rockville, MD: Substance Abuse and Mental Health Services Administration.

43. Shafeie Amiri M, Ariaie (012). Relationship between coping strategies, sensation seeking, and attachment styles on substance abuse trends. European Psychiatry: 27:1.

44. Stephen N. Campbell \& Annie Chang (2006) Reliability Testing and Validation of the Drug Attitude Scale, Substance Use \& Misuse, 41:5, 763-770, DOI: 10.1080/10826080500411452.

45. Terracciano, A.; Löckenhoff, C.E.; Crum, R.M.; Bienven, O.J.; \& Costa T.P. (2008). Five-factor model personality profiles of drug users. BiomMed Central Psychiatry, 8(22), 1-10, DOI: 10.1186/1471-244X-8-22.

46. Tugged, M. M. Fredrickson, B. L. \& Barrett, L. F. (2004). Psychological resilience and positive emotional granularity: Examining the benefits of positive emotions on coping and health. Journal of Personality, 72, 1161-1190.

47. Wong CF, Silva K, Kecojevic A, et al. (2013). Coping and emotion regulation profiles as predictors of nonmedical prescription drug and illicit drug use among high-risk young adults. Drug and Alcohol Dependence. 132(1-2):165-171.

48. World Health Organization (2004). Promoting mental health: concepts, emerging evidence, practice (Summary Report) Geneva: World Health Organization.

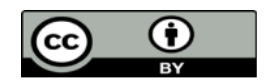

This work is licensed under Creative Commons Attribution 4.0 License

To Submit Your Article Click Here:

Submit Manuscript

DOI: $10.31579 / 2637-8892 / 146$

\author{
Ready to submit your research? Choose Auctores and benefit from: \\ $>$ fast, convenient online submission \\ $>$ rigorous peer review by experienced research in your field \\ $>$ rapid publication on acceptance \\ $>$ authors retain copyrights \\ $>$ unique DOI for all articles \\ $>$ immediate, unrestricted online access
}

At Auctores, research is always in progress.

Learn more https://auctoresonline.org/journals/psychology-and-mental-healthcare 